\title{
Assessment of the technical condition of deep mine shafts
}

\author{
Mikhail Pleshko ${ }^{1}$, Elena Kulikova ${ }^{1}$ and Andrey Nasonov ${ }^{2}$ \\ ${ }^{1}$ National University of Science and Technology MISIS (Moscow Institute of Steel and Alloys), \\ Leninskij Av., 4, Moskow, 119991, Russia \\ ${ }^{2}$ Shakhty Institute (branch) Platov South-Russian State Polytechnic University (NPI), Rostov Region, \\ Shakhty, pl. Lenina, 1, 346500, Russia
}

\begin{abstract}
In the present research, the estimation of actual durability of a shaft lining is made, considering the influence of factor of water filtration through "cold" seams of lining. This study is carried out on two vertical shafts of Donbas mines on eight sample plots. The data on the actual strength of the concrete lining after excavation and after 10 years of operation of the shaft were compared. The analysis of the data showed that the zone of "cold" seams is characterized by a decrease in the strength of concrete lining and an increase in the coefficient of variation of strength. It is established that the exhaustion of the resource of the shaft lining in the zone of leaking "cold" seams will occur in 16,9 years after the start of operation of the shaft, which is 4,6 years earlier than in the central areas of the lining stope.
\end{abstract}

\section{Introduction}

Shafts are the most important capital workings, linking the industrial site of mining enterprises with underground horizons. The efficiency of operation of the entire mine depends on their reliable and durable operation [1,2].

Comparative analysis of statistics of shaft sinking during the last period of the Soviet Union and modern Russia (Fig. 1) shows that the depth of shafts in all mining sectors increased by 1.5 - 2 times in 25 years [3-6]. There was a category of ultra-deep shafts, which according to the world classification is considered to be the working with a length of more than $1.5 \mathrm{~km}$.

The construction and operation of such facilities is a very complex technological task. The results of the survey of mine shafts in the Donbas showed that about $70 \%$ of all workings have some violations of lining and reinforcement. Many defects are formed already at the stage of construction, the duration of which at great depth of shafts reaches 8 - 10 years.

The real state of lining and reinforcement is determined by a large number of factors: geological and hydrogeological conditions, regularities of rocks deformation, peculiarities and quality of shaft sinking and exploitation, the influence of the treatment works, near-

\footnotetext{
* Corresponding author: mixail-stepan@mail.ru
} 
shaft workings, etc. Completeness of these data determines the accuracy of prediction of durability and reliability of the shaft lining during the long-term operation and is a very actual scientific task [7-14].

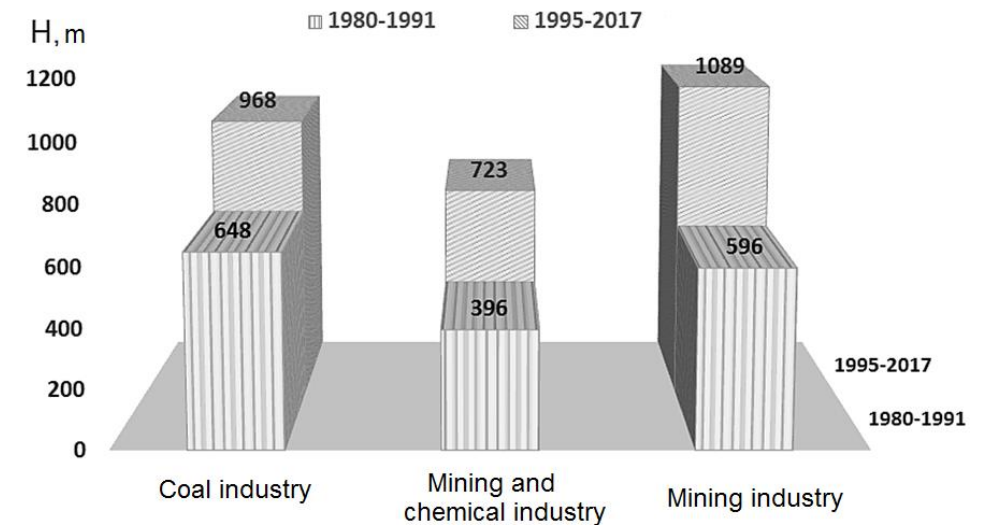

Fig. 1. Comparative statistics of average depths of vertical shafts in the mining industry

\section{Materials and Methods}

Currently, the regulatory framework for assessing the technical condition of vertical shafts in Russia is significantly outdated. Thus, in accordance with [14] the goal of the examination of lining or reinforcement is the identification of deviations from design decisions, regulatory requirements, and damage during operation.

Defects of the lining and the reinforcement are:

- microcracks and cracks in lining;

- $\quad$ weir and inrush in lining;

- $\quad$ crusting, bloating, mounds, nodules;

- $\quad$ openings and holes in the lining, bending and buckling of reinforcement;

- $\quad$ weakening of the attachment of the buntons;

- $\quad$ wear of conductors and lairs;

- $\quad$ corrosive wear of buntons;

- $\quad$ weakening of bolt connections;

- $\quad$ defects due to mechanical damage.

Work on the survey of the shaft include:

- $\quad$ analysis of design and implementation documentation;

- $\quad$ visual inspection;

- $\quad$ instrumental examination;

- $\quad$ determination of the actual parameters of the lining and reinforcement;

- determination of the strength of the material of the lining.

Based on the analysis of the data obtained during the survey, the category of the shafts is determined on a five-point scale and a protocol with conclusions and recommendations for its further operation is drawn up.

In the present study, in order to develop the technique, described above, an attempt is made to determine the actual durability of the shaft lining taking into account the influence of the water filtration factor that is not considered in the standard technique. This study is made in two vertical shafts of mines of Donbas on 8 sample plots. There were compared 
data on the actual strength of the concrete lining after excavation and after 10 years of operation of the shaft. Measurements were carried out in the central part of the stope and in the zone of the "cold" seam (at the junction of the stopes), where groundwater was filtered as leaks. To determine the strength of concrete widely tested shock pulse method with a device IPS-MG4 (certificate of conformity № 0000857) for measuring the strength of concrete was used. Each measurement result was an average of 15 measurements performed on one section of the shaft lining. The results of measurements were recorded in the measurement $\log$, on the basis of which further statistical data processing was performed. At the same time, the measurements were carried out by visual inspection of the condition of the lining, the presence of defects, manifestations of residual water flows, the quality of "cold" seams, etc.

\section{Results}

For a more accurate assessment of the water filtration factor, a refined classification of related shaft lining defects has been developed. Its main elements are presented below.

On intensity of process of filtration of water in a shaft, it is possible to allocate:

- dampness - filtration of water, causing humidity of the concrete lining and the formation of a separate wet spots on its surface;

- downpour - filtration of water in the form of drops, which can be observed in large areas where the concrete lining has insufficient water resistance;

- concentrated leaks - places where there is a noticeable flow of water.

By the duration, the manifestation of filtration can be permanent and seasonal, for example, in spring and autumn. In some cases, filtration decreases spontaneously after a while and disappears. Often, after the filtration disappearing in one place, it appears in the neighboring areas of the shaft. This phenomenon can be explained by the local selfcompaction of the concrete. One of the reasons for self-compacting concrete can be clogging it port impurities that are contained in groundwater. Self-compaction can also be caused by chemical processes in the concrete under the influence of chemical agents contained in ground water. The conversion of free calcium oxide hydrate into calcium carbonate can occur in presence of free carbon dioxide in water. Calcium and magnesium bicarbonates contained in water can also react with calcium oxide hydrate. The resulting calcium and magnesium carbonate particles are deposited on the walls of the pores and, gradually reducing their cross-section, tampon the pores in the concrete.

On the sections of the shafts in areas having a concentrated leak, there is a deposition of red-brown, and sometimes white sinters, carried-out by water. White sinters are composed in the form of a dense formless mass or in the form of stalactites and consist mainly (up to $65 \%$ ) of calcium carbonate. In most cases, sinters of white color are available in areas of shafts laid in limestone. Underground waters in this case have strong natural carbonation, also there is a partial leaching of lime of a cement mortal from lining.

Red-brown sinters have the form of silt, sometimes foamy and mainly consist of iron oxide hydrate (up to 22\%) and are the product of groundwater removal [15].

Concentrated leaks in the shafts are observed mainly in the zone of "cold" seams of lining. During operation, the impact of leaks leads to intensive corrosion of concrete and an additional decrease in its strength. An example of a defective "cold" seam of one of the test sections is shown in Fig. 2. 


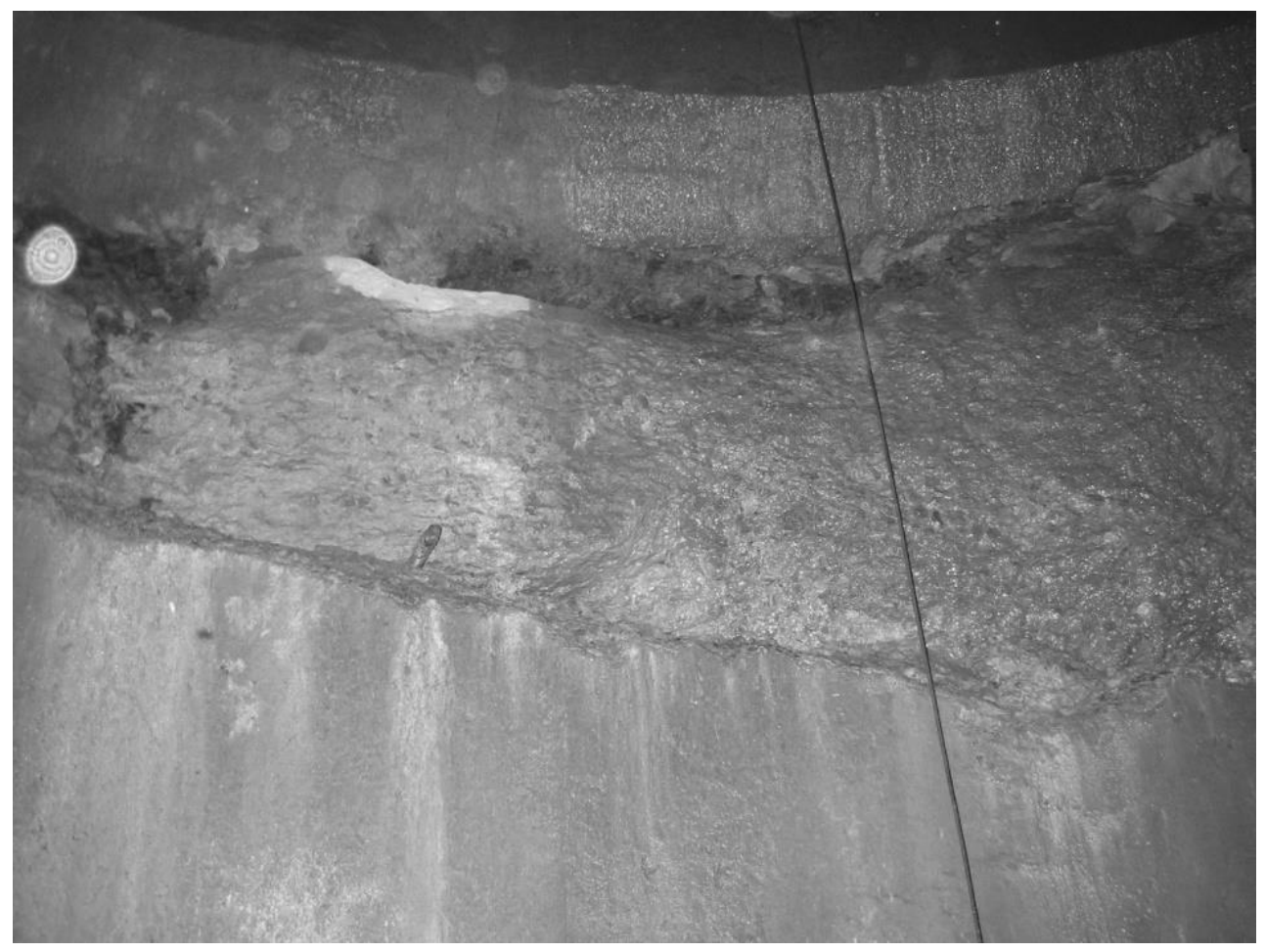

Fig. 2. Example of a defective "cold" seam in the vertical shaft lining.

For a more accurate assessment of the impact of water filtration in the form of leaks on the strength of concrete lining there were made comparative measurements of the strength of concrete in the areas of leaking "cold" seams and in the central part of the stope. As a result of data processing, an array of data on 40 lining points was obtained at 8 pilot sites of two trunks at the time of operation and after 10 years of operation of the shafts.

These data are summarized in table 1 . In this table the following notation was used: $R_{i}$ is the strength of the concrete lining, determined by the results of 15 measurements by device IPS-MG4; $R_{m}$ - the average strength of the concrete lining; $S_{m}-$ standard deviation; $V_{m}-$ variation coefficient of strength of concrete, $\%$.

The analysis of the presented data shows that the zone of "cold" seams is characterized by a decrease in the strength of concrete lining and an increase in the coefficient of variation of strength. After ten years of operation in the area of "cold" seams, there was a more intensive decrease in the strength of concrete, which can be explained by the negative impact of groundwater filtration to the shaft.

On the basis of the generalized estimation of the strength of the concrete lining the next stage of the assessment of the technical condition of the deep shafts was the determination of the actual durability of lining, which means the failure of the underground structure during a given period of operation at a minimum cost of its maintenance.

According to A.A. Shilin's research, reliability of bearing structures of underground facilities is changed during the operation according to the following dependence [16]:

$$
\beta(t)=\beta(0)\left[1-\frac{t^{3}}{\tau_{0}^{3}}\right],
$$

where $\beta$ - the reliability index; $\tau_{0}$ - the time corresponding to the decay of reliability, years; $t$ - time of operation of underground facilities, years. 
Using this expression, generalized graphs of changes in the reliability index of the investigated sections of the shaft lining depending on the time factor are constructed (Figure 3).

Table 1. Statistics on the actual strength of the shaft lining, MPa

\begin{tabular}{|c|c|c|c|c|}
\hline \multirow{2}{*}{ Indicator } & \multicolumn{2}{|c|}{ Central part of the lining ring } & \multicolumn{2}{|c|}{ Area of "cold" seam } \\
\hline & $t=0$ & $\mathrm{t}=10$ years & $\mathrm{t}=0$ & $\mathrm{t}=10$ years \\
\hline $\mathrm{R}_{1}$ & 27,3 & 25,9 & 33,2 & 12,6 \\
\hline $\mathrm{R}_{2}$ & 14,8 & 14,3 & 16,7 & 12,8 \\
\hline $\mathrm{R}_{3}$ & 14,3 & 13,3 & 15,9 & 19,5 \\
\hline $\mathrm{R}_{4}$ & 25,4 & 23,5 & 18,0 & 19,4 \\
\hline $\mathrm{R}_{5}$ & 17,0 & 17,2 & 22,1 & 14,6 \\
\hline $\mathrm{R}_{6}$ & 31,8 & 16,9 & 25,6 & 17,8 \\
\hline $\mathrm{R}_{7}$ & 28,7 & 21,7 & 29,6 & 33,8 \\
\hline $\mathrm{R}_{8}$ & 21,0 & 20,2 & 14,9 & 11,6 \\
\hline $\mathrm{R}_{9}$ & 22,4 & 21,6 & 19,6 & 18,9 \\
\hline $\mathrm{R}_{10}$ & 24,1 & 23,3 & 24,7 & 13,9 \\
\hline $\mathrm{R}_{11}$ & 18,9 & 18,3 & 29,4 & 25,1 \\
\hline $\mathrm{R}_{12}$ & 28,5 & 27,6 & 26,5 & 26,1 \\
\hline $\mathrm{R}_{13}$ & 29,5 & 28,7 & 25,6 & 18,4 \\
\hline $\mathrm{R}_{14}$ & 22,1 & 21,5 & 26,5 & 14,7 \\
\hline $\mathrm{R}_{15}$ & 21,0 & 19,7 & 22,5 & 9,9 \\
\hline $\mathrm{R}_{16}$ & 25,6 & 25,1 & 23,8 & 22,9 \\
\hline $\mathrm{R}_{17}$ & 26,3 & 25,8 & 21,9 & 23,2 \\
\hline $\mathrm{R}_{18}$ & 28,4 & 27,9 & 21,9 & 23,5 \\
\hline $\mathrm{R}_{19}$ & 27,9 & 27,5 & 20,7 & 9,7 \\
\hline $\mathrm{R}_{20}$ & 26,5 & 27,6 & 18,3 & 10,8 \\
\hline $\mathrm{R}_{21}$ & 20,6 & 20,4 & 19,2 & 14,8 \\
\hline $\mathrm{R}_{22}$ & 24,2 & 24,0 & 18,5 & 24,7 \\
\hline $\mathrm{R}_{23}$ & 25,5 & 25,4 & 16 & 14,6 \\
\hline $\mathrm{R}_{24}$ & 33,1 & 33,1 & 17,9 & 16,8 \\
\hline $\mathrm{R}_{25}$ & 31,9 & 32,9 & 17,3 & 18,0 \\
\hline $\mathrm{R}_{26}$ & 19,7 & 18,7 & 19,8 & 18,1 \\
\hline $\mathrm{R}_{27}$ & 24,7 & 23,7 & 21,5 & 18,2 \\
\hline $\mathrm{R}_{28}$ & 25,5 & 18,7 & 22,8 & 15,7 \\
\hline $\mathrm{R}_{29}$ & 22,3 & 21,2 & 21,0 & 18,4 \\
\hline $\mathrm{R}_{30}$ & 31,9 & 30,0 & 22,6 & 10,3 \\
\hline $\mathrm{R}_{31}$ & 33,3 & 31,1 & 22,3 & 15,3 \\
\hline $\mathrm{R}_{32}$ & 24,4 & 14,3 & 22,8 & 11,0 \\
\hline $\mathrm{R}_{33}$ & 27,8 & 15,2 & 18,7 & 18,4 \\
\hline $\mathrm{R}_{34}$ & 21,7 & 19,8 & 37,1 & 21,6 \\
\hline $\mathrm{R}_{35}$ & 27,3 & 26,4 & 23,6 & 21,3 \\
\hline $\mathrm{R}_{36}$ & 28,7 & 21,0 & 27,4 & 13,9 \\
\hline $\mathrm{R}_{37}$ & 29,2 & 18,9 & 23,5 & 12,8 \\
\hline $\mathrm{R}_{38}$ & 22,4 & 19,8 & 28,6 & 25,7 \\
\hline $\mathrm{R}_{39}$ & 26,8 & 25,7 & 23,8 & 25,7 \\
\hline $\mathrm{R}_{40}$ & 28,5 & 19,5 & 24,0 & 23,7 \\
\hline $\mathrm{R}_{\mathrm{m}}$ & 25,28 & 22,68 & 22,65 & 17,96 \\
\hline $\mathrm{S}_{\mathrm{m}}$ & 4,61 & 5,01 & 4,69 & 5,44 \\
\hline $\mathrm{V}_{\mathrm{m}}$ & $18,24 \%$ & $22,07 \%$ & $20,69 \%$ & $30,29 \%$ \\
\hline
\end{tabular}




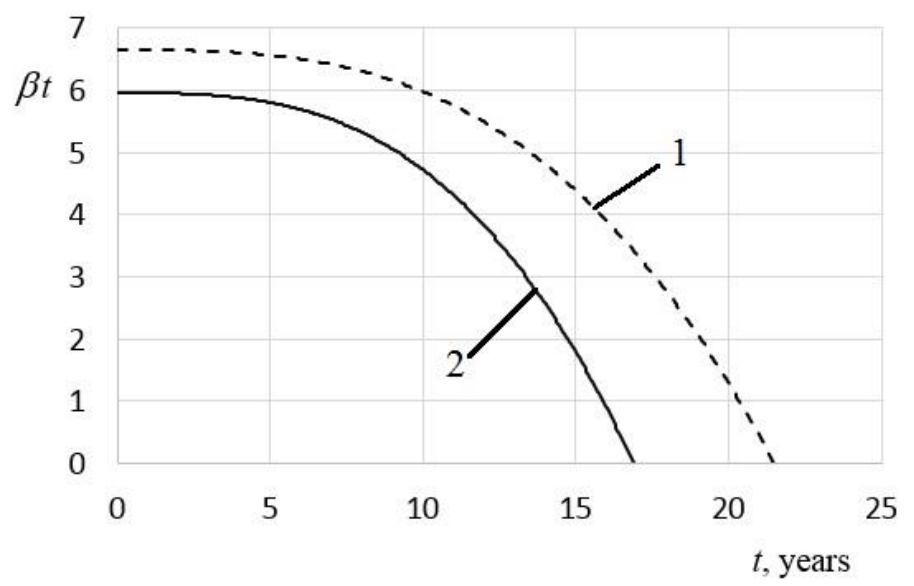

Fig. 3. Changing the reliability of the shaft lining depending on the service time: 1 - in the central areas of the stope; 2 - in the area of the leaking "cold" seams

It is established that the exhaustion of the resource of the shaft lining in the zone of leaking "cold" seams will occur in 16,9 years after the start of operation of the shaft, which is 4,6 years earlier than of lining in the central areas of the lining stopes.

\section{Conclusions}

Studies have shown that the assessment of the technical condition of vertical shafts is a complex geotechnical problem that requires a comprehensive account of many factors. One of them is the filtration of water into the shaft through the defective places of the lining. This process, over time, leads to a more intensive decrease in the strength of concrete lining in the zone of active leaks, especially the "cold" seams of the stopes in comparison with normal areas. Because of this, the depth of the shaft area lining are formed with different residual resource of the reliability. There is a need for an earlier repair of leaking "cold" seams with a corresponding increase in the cost of the current maintanance of the shaft. To prevent this situation, it is advisable to ensure the high quality of the "cold" seams at the stage of sinking, particularly by switching to progressive parallel technological schemes of sinking, the use of high-performance concrete compositions, additional waterproofing of the lining, the use of a formwork pallet with more complex spatial geometry. It is especially important to implement such measures in deep and ultra-deep shafts, where hundreds of flowing "cold" seams can potentially be formed along the length of the shaft.

\section{References}

1. V.I. Golik, Z.M. Hasheva, S.V. Galachieva, The Social Sciences (Pakistan), 10(6) (2015)

2. V.I. Golik, Y.I. Razorenov, O.N. Polukhin, International Journal of Applied Engineering Research, 10(17) (2015)

3. M.S. Pleshko, O.V. Pashkova, A.A. Nasonov, Gornyj zhurnal, 3 (2015)

4. M. Pleshko, I. Voinov, A. Revyakin, MATEC Web of Conferences series, 106, 05004 (2017)

5. B. Meskhi, M. Pleshko, Y. Buligin, L. Alexeenko, M. Molev, IOP Conference Series: Earth and Environmental Science 012217 (2017). 
6. F.I. Yagodkin, A.Y. Prokopov, M.S. Pleshko, A.N. Pankratenko, IOP Conference Series: Earth and Environmental Science Series, 062014 (2017)

7. M.D. Molev, S.G. Stradanchenko and S.A. Maslennikov, ARPN Journal of Engineering and Applied Sciences, 10(16) (2015)

8. F. Yagodkin, M. Pleshko, A. Prokopov, Procedia Engineering, 206 (2017)

9. M.S. Pleshko, Y.V. Vcherashnyaya, A.A. Nasonov, Gornyi Zhurnal, 10 (2016)

10. M.S. Pleshko, S.G. Stradanchenko, S.A. Maslennikov, O.V. Pashkov, ARPN Journal of Engineering and Applied Sciences, 10(1) (2015)

11. M. Pleshko, B. Meskhi, M. Pleshko, MATEC Web of Conferences, 170, 03023 (2018)

12. A. Pankratenko, M. Pleshko and A. Isaev, MATEC Web of Conferences, 7, 02026 (2018)

13. D. Shuxue, J. Hongwen, C. Kunfu, X. Guo'an, M. Bo, International Journal of Mining Science and Technology, 27 (2017)

14. RD 03-422-01. Methodical instructions on carrying out expert examinations of mine lifting installations. Moscow (2002)

15. Yu.N. Kulikov, Improving the reliability and durability of collector tunnels. Proceedings "Construction of underground structures". (Moscow, MGI, 1984)

16. A.A. Shilin, PhD Thesis, (Moscow, MGGU 2002) 